\title{
Relaciones públicas en un mundo interconectado
}

\section{Public relations in an interconnected} world

EDITORIAL

\section{Ruth S. Contreras Espinosa}

\author{
Universitat de Vic-Universitat Central de Catalunya \\ Profesora del Departamento de Comunicación. Editora de la revista Obra Digital. \\ ruth.contreras@uvic.cat \\ orcid.org/0000-0002-9699-9087
}

\section{Resumen:}

Muchos expertos, profesionales y autores están usando los nuevos medios de la misma manera que usaron otros medios como la televisión, para descargar mensajes. Pero para que las relaciones públicas utilicen completamente los medios digitales y las redes sociales, los profesionales deben regular las relaciones públicas como un paradigma de gestión estratégica. Todo esto podría parecer que es la última moda en las relaciones públicas, pero no es así, porque los nuevos medios tienen el potencial de hacer que la profesión sea más global y estratégica.

\section{PALABRAS CLAVE}

Relaciones Públicas, comunicación, investigación, redes sociales.

\section{Abstract:}

Many experts, professionals and authors are using the new media in the same ways they used television, as a means of dumping messages. But, for public relations to fully use digital media and social media, professionals must regulate public relations as a strategic management paradigm. All this might come as the latest fad in public relations, but the new media have the potential to make the profession more global and strategic.

\section{KEYWORDS}

Public relations, communication, research, social media. 
El conocimiento de las relaciones públicas ha crecido significativamente en los últimos 30 años y continúa evolucionando para establecerse como una disciplina importante. Aunque este dato puede llegar a ser alentador, este crecimiento no es igual en el sentido que el foco de la construcción se ha limitado principalmente en sitios como los Estados Unidos de América y algunos países de Europa.

Como respuesta a ello, editores de diversas revistas académicas hemos dado la bienvenida a artículos relacionados con el tema de las relaciones públicas, y cada vez más, se publica un mayor número de investigaciones cercanas a las relaciones públicas. Esto ha contribuido a dar a conocer estudios sobre diferentes prácticas en diversas regiones, y en un mundo interconectado. Aunque gran parte de la literatura sobre relaciones públicas está publicada en inglés y, no haya recibido una mayor difusión, el número de publicaciones en otros idiomas crece y se extiende. El cuerpo existente de conocimiento de las relaciones públicas ya no es solo en un idioma, ni es silencioso o hace solo referencia a las prácticas de las relaciones públicas y al potencial de algunas regiones. Esta situación ha cambiado.

La revista Obra Digital, ha sentido la responsabilidad de atender desde una perspectiva científica a esta área. Como revista internacional cuyo eje es la comunicación en cualesquiera de sus diferentes formulaciones y dimensiones, nos hemos acercado a las relaciones públicas desde hace tiempo con artículos relacionados en otros números de la revista. Nuestro número trece, correspondiente a los meses de septiembre de 2017 a enero de 2018, se nutrió de 9 artículos bajo el título "Retos y oportunidades de las relaciones públicas: formación, investigación y salud". Pero en total, la revista Obra Digital, ha publicado hasta ahora 19 trabajos relacionados, de una u otra forma con las relaciones públicas enmarcadas dentro de la comunicación organizacional y estratégica, y con el papel que las relaciones públicas juegan dentro del ámbito digital.

Como aún quedan incógnitas pendientes por resolver, hemos decidido publicar un nuevo número. El lector podrá disfrutar en este monográfico de las relaciones públicas desde el ámbito de la comunicación gracias a contenidos que han sido agrupados en torno a dos ejes: por una parte, las redes sociales y el ámbito digital como soporte para las relaciones públicas y, por la otra, los estudios de caso en referencia a contenidos vinculados con la responsabilidad social corporativa, el tercer sector o la recaudación de fondos. La investigación centrada en las relaciones públicas se vuelve cada vez más global tanto en la teoría como en la práctica. Existe la necesidad de entender mejor todos aquellos temas sociales, políticos o económicos, y para ello se necesita de una base de conocimientos amplios, para abordar todas aquellas cuestiones relacionadas con el cambio en estos entornos. Culbertson y Jeffers (1992) ya destacaron en su momento la importancia de lo que llamaron contextos sociales, políticos y económicos para la práctica de las relaciones públicas. También existe la necesidad de ver que se están usando los nuevos medios de la misma manera que se usaron anteriormente medios como la televisión o la radio, siempre con la intención de descargar mensajes. Pero, para que las relaciones públicas utilicen completamente los medios digitales y las redes sociales, los profesionales deben regular las relaciones públicas como un paradigma de gestión estratégica. No solo por ser la última moda en las relaciones públicas, los nuevos medios tienen el potencial de hacer que la profesión sea más global y estratégica.

En los artículos de este número 15, los autores además de describir diversas prácticas 
de relaciones públicas en algunas regiones, contextualizan dicha práctica al vincularla con variables socioculturales. En el Manual de Relaciones Públicas Globales, Sriramesh y Verčič, (2003, 2009), muestran que hay muchas idiosincrasias en la práctica de relaciones públicas en todo el mundo que reflejan cuales son las diferencias culturales. Además, se centran en el uso de tácticas y técnicas vinculadas a las social media y también en cuanto al análisis de casos concretos sobre realidades comunicativas que las distintas organizaciones están viviendo. Las relaciones con los medios son cada vez más importantes. Esperamos que al adoptar este enfoque, este monográfico proporcione algunas bases para establecer un cuerpo holístico de conocimiento. Creemos que los autores, como expertos en relaciones públicas, están en una buena posición para describir el estado de las relaciones públicas en su región, así como relacionar dicha práctica con variables relevantes.

Los trabajos reunidos nos confirman el interés para la comunidad académica en este tema. Esta publicación debería resultar beneficiosa para los profesionales de relaciones públicas y comunicación. Además, debería ser útil para estudiantes especializados en relaciones públicas. Al discutir la práctica de las relaciones públicas como una función sociocultural, económica, mediática y activista en el que las organizaciones globales deben operar, este monográfico señala el camino hacia nuevos enfoques de las relaciones públicas en este mundo interconectado.

El futuro de las relaciones públicas a nivel mundial es prometedor. Sin embargo, el desafío para los académicos es proporcionar una base de conocimiento solida que pueda ayudar a impulsar la profesión hacia una mayor sofisticación y efectividad.

\section{Referencias}

Culbertson, H. M., y Jeffers, D. W. (1992). The social, political, and economic contexts: Keys in educating true public relations professionals. Public Relations Review, (11), 5-21.

Sriramesh, K. y Verčič, D. (2003). The global public relations handbook: Theory, research and practice. Mahwah, NJ: Lawrence Erlbaum Associates.

Sriramesh, K. y Verčič, D. (2009). The global public relations handbook: Theory, research and practice (Expanded and revised edition). New York and London: Routledge.

\section{Ruth S. Contreras Espinosa}

Editora de la revista Obra Digital. Profesora del Departamento de Comunicación. 